Check for updates

Cite this: Lab Chip, 2019, 19, 1916

Received 31st January 2019,

Accepted 23rd April 2019

DOI: $10.1039 / c 9 l c 00108 e$

rsc.li/loc

\section{Monitoring transient cell-to-cell interactions in a multi-layered and multi-functional allergy-on-a- chip system $\uparrow$}

\author{
Mario Rothbauer, (iD $\ddagger^{\mathrm{ab}}$ Verena Charwat, $\$ \S^{\mathrm{c}}$ Barbara Bachmann, $\xi^{\text {abd }}$ \\ Drago Sticker, iD + Richard Novak, iD f Heinz Wanzenböck, iDg \\ Richard A. Mathies ${ }^{f}$ and Peter Ertl iD *ab
}

We have developed a highly integrated lab-on-a-chip containing embedded electrical microsensors, $\mu$ degassers and pneumaticallyactuated micropumps to monitor allergic hypersensitivity. Rapid antigen-mediated histamine release (e.g. $\mathrm{s}$ to $\mathrm{min}$ ) and resulting muscle contraction ( $<30 \mathrm{~min}$ ) is detected by connecting an immune compartment containing sensitized basophile cells to a vascular co-culture model.

\section{Introduction}

Cell to cell communication and transient cell response to external stimuli are vital in all multicellular organisms to react to changing environments. ${ }^{1}$ Cross-talk between cells, either by direct cell-cell contact or indirectly via signalling molecules, plays a crucial role in human health ${ }^{2-6}$ and disease. ${ }^{7-12}$ These cell-cell interactions can be of permanent nature in the case of tight or gap junction formation, or based on fast, transient signalling between the same and different cell types. Especially short-lived transient cell-to-cell interactions via secretion of signalling molecules are essential, since multicellular assemblies must coordinate complex physiological mecha-

\footnotetext{
${ }^{a}$ Faculty of Technical Chemistry, Vienna University of Technology, Getreidemarkt 9, 1060 Vienna, Austria. E-mail: peter.ertl@tuwien.ac.at

${ }^{b}$ Austrian Cluster for Tissue Regeneration, 1200 Vienna, Austria

${ }^{c}$ Department of Biotechnology, University of Agricultural Resources and Life Sciences, Muthgasse 18, 1090 Vienna, Austria

${ }^{d}$ AUVA Research Centre, Ludwig Boltzmann Institute for Experimental and Clinical Traumatology, 1200 Vienna, Austria

${ }^{e}$ Department of Pharmacy, University of Copenhagen, Universitetsparken 2, 2100 Copenhagen, Denmark

${ }^{f}$ Department of Chemistry, University of California at Berkeley, Lewis Hall, Berkeley, California, USA

${ }^{g}$ Faculty of Electrical Engineering, Vienna University of Technology, Gußhausstr. 25-25a, 1040 Vienna, Austria

$\dagger$ Electronic supplementary information (ESI) available. See DOI: 10.1039/ c9lc00108e

\$ These authors contributed equally.

§ Current address: University of California at Berkeley, 370 Hearst Memorial Mining Building \#1760, Berkeley, CA 94720.
}

nisms. These mechanisms are known to include neuronal signaling, ${ }^{13}$ bone formation ${ }^{14}$ and immune response $^{15,16}$ but also pathological conditions such as tumour growth, ${ }^{17}$ cardiovascular disease ${ }^{18}$ and allergies. ${ }^{19}$ In particular, during allergic reactions the interaction between immune and different tissue cell types occur immediately following the exposure to an antigen, which leads to release of soluble factors resulting in early phase allergic reactions including vascular dilation and smooth muscle contractions within minutes as illustrated in Fig. 1a. ${ }^{20,21}$ In the most common type of allergic reaction, type I (e.g., IgE-mediated or anaphylactic-type) hypersensitivity (20\% of adults) repeated exposure to an allergen results in an overproduction of IgE-antibodies by B-cells, ${ }^{20}$ follow on sensitization, ${ }^{22}$ and binding of these antibodies to the FceRI ${ }^{23}$ receptors of tissue mast cells and blood basophils. Upon reexposure to the antigen and crosslinking to the antibodies

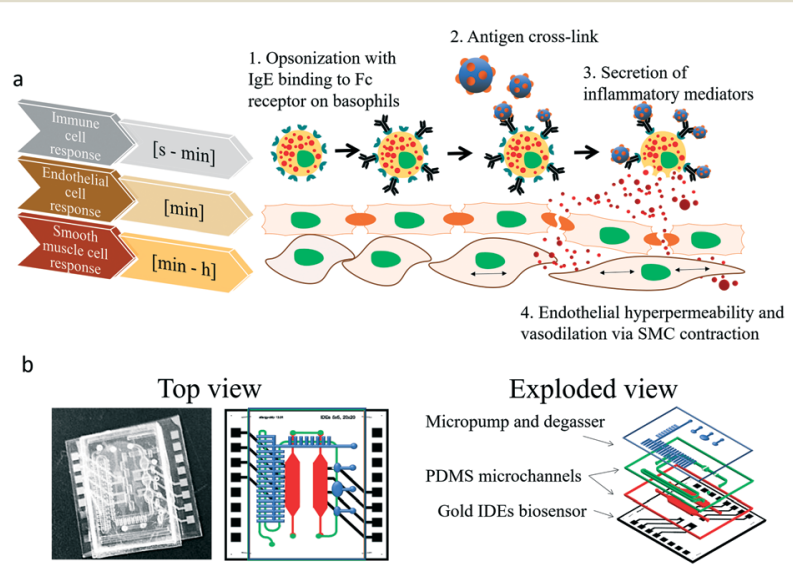

Fig. 1 (a) Basic overview of the transient cellular responses during type I IgE-mediated allergic responses in the range of seconds to hours resulting in endothelial hyperpermeability and smooth muscle cell (SMC) contraction. (b) Top view and layer-by-layer assembly of the allergy-on-a-chip system comprised of liquid handling (micropumps and micro degassers; blue and green layer) and microfluidic layers with integrated impedance biosensors for cell-based non-invasive monitoring (red layer). 
triggers the release of histamine ${ }^{24}$ and other chemical mediators as well as the synthesis of inflammatory molecules, causing the early phase of allergic reactions resulting in contraction of smooth muscle cells and increased vascular permeability. ${ }^{25}$ This signalling cascade ultimately leads to the typical symptoms related to allergies from rhinitis and mucus secretion in mild to moderate cases to hypotension and shock in anaphylaxis. With allergies becoming increasingly common, ${ }^{26}$ research into novel treatment options such as vaccines and immunotherapy has gained world-wide momentum. ${ }^{27} \mathrm{Al}-$ though a deeper understanding of the complex cellular processes that govern immune responses are crucial in basic and applied research, such transient cell-to-cell interactions are exceedingly difficult to monitor using conventional optical methods. To overcome these drawbacks a number of microfluidic cell cultures systems containing embedded biosensors $^{28}$ have been developed over the last decade to allow efficient cell manipulation, stimulation and analysis of cell-tocell interactions in vitro at the micro-scale under physiologi$\mathrm{cal}^{29}$ and highly controllable microenvironment conditions. $^{30,31}$ For instance, microfluidic devices have been employed to analyse $\mathrm{B}$ - and T-cell repertoires within populations of single cells, ${ }^{32}$ to conduct antibody screening, ${ }^{32}$ aid in allergy diagnosis ${ }^{33,34}$ and accelerate cancer immunology. ${ }^{35}$ Among these, microfluidic devices containing integrated electrical biosensors have demonstrated the ability to e.g. study dynamic interactions between tumor cells, immune cells and resident tissue ${ }^{36}$ as well as a variety of hetero- and homogenous cell-to-cell interactions. ${ }^{37-39}$

To monitor transient immunological reactions that occur in type I allergy (see Fig. 1), we present a multi-layered, membrane-based and sensor-integrated lab-on-a-chip microdevice that performs automated fluid handling routines, cellloading protocols and continuous, non-invasive bioimpedance spectroscopy. While the integration of micropumps and micro-degassers enable rapid control over the cellular microenvironment with nano-liter dead volume, the embedded electrical microsensors enable the detection of cellular responses with millisecond resolution (see Fig. $\mathrm{S} 1 \dagger$ for detailed set-up). This highly integrated microfluidic device contains two spatially separated compartments to (1) maintain a vascular co-culture model comprising of endothelial cell monolayers and smooth muscle cells and (2) an immune cell cultivation chamber located upstream, where the allergic reaction takes place. Both tissue chambers contain embedded impedance sensors to (a) monitor rapid basophil degranulation during type I and time-dependent regeneration events as well as (b) to detect dynamic cell-to-cell interactions between endothelial and smooth muscle as a result to antigenmediated histamine release of basophile cells. Using the highly integrated biochip design shown in Fig. 1b, we now attempt to demonstrate the technological ability to evaluate cell signalling cascades and to show that secondary cellular responses such as muscle contraction can be used to amplify otherwise difficult to detect cellular signals (e.g. release of histamines).

\section{Results and discussion}

\subsection{Characterization of on-chip micro-degassers, micro- pumps and thin-film gold impedance sensors}

The integrated micropump provides programmable perfusion of medium and reagents at $\mathrm{nL}$ dead volume and is based on a four-step actuation procedure of three serially-connected microvalves. ${ }^{40,41}$ Fluid displacement is defined by the geometry of the ellipsoid central microvalve featuring a diameter of $2 \mathrm{~mm}$ length and $1 \mathrm{~mm}$ width and $100 \mu \mathrm{m}$ height, which corresponds to a volume of $0.6 \mu \mathrm{l}$ per pump stroke. Actuation pressures and step times between valves can be adjusted to control net flow velocities, peak shear forces and peristaltic profiles (see Fig. S-2† for detailed characterizations). We characterized micropump operation over a range of actuation times and pressures in order to optimize cell culture perfusion conditions. Fig. 2a shows five actuation cycles and actuation step time of $25 \mathrm{~ms}$ resulting in positive pump strokes with peak values around $38 \pm 2 \mu \mathrm{l}$ and actuation duration for individual strokes of around $100 \mathrm{~ms}$. Increase of actuation step time to $75 \mathrm{~ms}$ as shown in Fig. S-2a $\uparrow$ decreases the peak values to $31 \pm 1 \mu \mathrm{l}$ with an average actuation time around 300 ms. Incomplete execution of the actuation protocol due to inertia of the flexible membrane resulted in negative backflow of around $20 \pm 1 \mu \mathrm{l}$ with an average backflow duration of 50 ms. In a next set of experiments, the influence of actuation pressure on micropump peak values was evaluated in the presence of linear increase in actuation pressure between 10$40 \mathrm{kPa}$. Fig. S-2c-f $\dagger$ shows that not only step time but also actuation pressures can effectively influence micropump performance resulting in varying flow profiles and flow rates. As an example, highest peak values were observed for $40 \mathrm{kPa}$ actuation pressure corresponding to $38 \pm 3 \mu \mathrm{l}$ pump strokes. When reducing the actuation pressure displaced volume marginally decreased to $22 \pm 1,14 \pm 1$ and $9 \pm 1 \mu \mathrm{l}$ for 30 to $10 \mathrm{kPa}$, respectively.

In a more detailed study (see Fig. S-2c $\dagger$ ) average micropump flow rates were evaluated for $10-45 \mathrm{kPa}$ actuation pressure and 1-100 $\mathrm{Hz}$ actuation frequency or $0.3-8.5 \mathrm{~ms}$ step time. Results of the study revealed linear increase of average net flow when using actuation frequencies below $20 \mathrm{~Hz}$. Above this $20 \mathrm{~Hz}$ threshold, flow rates gradually decreased, despite the increasing actuation pressures indicating that valves did not fully close in the presence of higher actuation frequencies. This means that at $10 \mathrm{~Hz}$ actuation frequencies similar flow rates of approximately $6 \mu \mathrm{min}^{-1}\left(0.25 \mathrm{dyn} \mathrm{cm}^{-2}\right)$ are obtained for $45 \mathrm{kPa}$ and $30 \mathrm{kPa}$ actuation pressures. The ability to tune flow rates adjust peak shear forces and regulate fluid flow directions using integrated micropumps provides a close controlled and, reproducible cell culture conditions that can be optimized for any cell type.

The formation of microbubbles as shown in Fig. S-3† constitutes a prevalent obstacle to microfluidic cell cultures systems in general, since bubbles can form on nucleation sites and obstruct flow and increase shear stress to cell layers. Systems that rely on pneumatically-driven micropumps where 
a

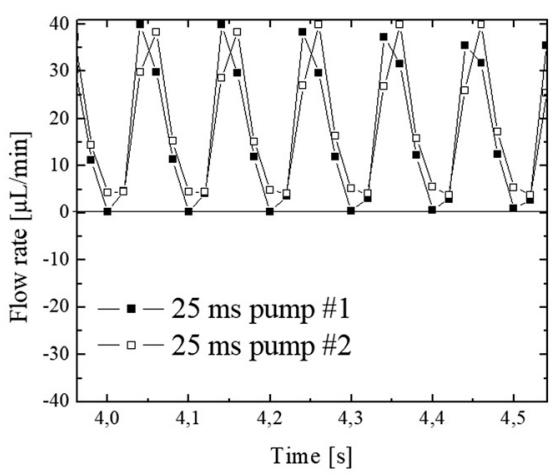

b

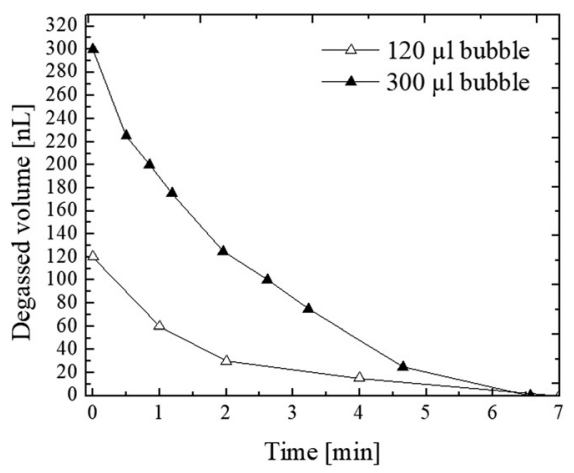

$\mathrm{C}$

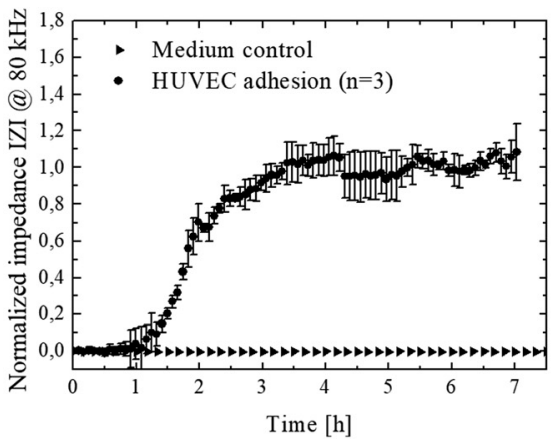

Fig. 2 (a) Peak flow profile of two parallel on-chip integrated micropumps for $25 \mathrm{~ms}$ actuation step time. (b) Removal of $120 \mathrm{~nL}$ and $30 \mathrm{~nL}$ air bubbles using the semi-permeable $\mu$ degasser at $-60 \mathrm{kPa}$ negative pressure. (c) Representative impedance time-trace for endothelial cell adhesion and establishment of confluent endothelial monolayers during the first 7 hours of on-chip cultivation at a frequency of $80 \mathrm{kHz}$.

pressurized air actuation is used face an additional challenge since, PDMS membranes valves are gas-permeable and facilitate evaporation of medium while the pressurized gas for actuation can dissolve into and potentially saturate the medium. To address these challenges, we have developed an integrated low dead volume degasser design. The on-chip integrated micro degassing system was evaluated for its capacity to remove microbubbles from the cell cultivation chamber. Fig. S-4ab $\dagger$ shows that nucleated bubbles tend to form, accumulate and increase at $37^{\circ} \mathrm{C}$ within the microfluidic cultivation chamber with an average growth rate of 15 $\mathrm{nl} \mathrm{min}^{-1}$ leading to several $\mathrm{kOhms}$ increase in impedance signal. A negative pressure of $-60 \mathrm{kPa}$ was applied to the semipermeable $\mu$ degassing layer see Fig. $2 \mathrm{~b}$ resulting in an aver- age degassing time of around 6.5 min corresponding to a degassed bubble volume of $32 \pm 16 \mu \mathrm{min}^{-1}$. Interestingly, when increasing the microchannel height from $60 \mu \mathrm{m}$ to $100 \mu \mathrm{m}$ at a constant channel area the time for bubble removal was similar even though the bubble volume increased from $120 \mathrm{nl}$ to $300 \mathrm{nl}$. Results of a long-term study demonstrated that bubble-free operation of the microfluidic cell cultures system can be accomplished over several weeks when using a serpentine-shaped degasser. The elimination of microbubble formation in the cell culture chamber as shown in Fig. S-4c-e $\uparrow$ is particularly crucial when employing bioimpedance sensors that readily detect dielectric changes in the sensing volume to investigate most transient soluble cell interactions under constant conditions.

Next, the embedded bioimpedance sensors were characterized to determine optimum AC frequencies for detecting substrate adhesion and monolayer formation of human umbilical vein endothelial target cells. Sensitivity was calculated as a change in impedance of confluent endothelial cell monolayers in comparison to blank electrodes. Fig. S-4f $\dagger$ shows that the silicon-nitride coated, interdigitated electrode structures showed highest sensitivity to endothelial cell adhesion at a frequency range between $80 \mathrm{kHz}$ and $100 \mathrm{kHz}$. Normalized impedance-time traces recorded at $80 \mathrm{kHz}$ of endothelial cells adhesion and spreading is shown in Fig. 2c. A rapid increase of $290 \pm 60$ Ohms per $\mathrm{h}(100 \%)$ was observed during the first 3.5 hours indicating efficient cell adhesion at the sensor surface, followed by cell spreading events that resulted in a plateau phase indicating full sensor coverage and establishment of a stable cell barrier after 8 hours. Results of the sensor evaluation demonstrate the ability of the passivated and throughout silicon nitride-coated $(50 \mathrm{~nm})$ impedance sensors to continuously monitor the endothelial cell barrier integrity during allergic reactions resulting in endothelial hyperpermeability (see also Fig. 1a for cascade overview).

\subsection{On-chip degranulation of of RBL-2H3 basophil cells}

Since the crucial step in our chip-based allergic signaling cascade is the release of inflammatory mediators such as histamine by basophil cells, speed and efficiency of antigenmediated degranulation of IgE opsonized RBL-2H3 basophils was evaluated using a methylene blue assay and impedance measurements. Degranulation of IgE opsonized basophil cells was initiated with the addition of $0.03 \mu \mathrm{g} \mathrm{ml}^{-1}$ of $\mathrm{rPhI}$ antigen into DPBS and supplemented RPMI 1640 medium. Fig. S-5a $\nmid$ shows that independent from the media composition opsonized basophil cells degranulated within $7 \mathrm{~min}$ of exposure to the rPhI antigen. However, while complete degranulated was observed in DPBS, $40 \%$ of the basophil cells remained granulated in the presence of in RPMI 1640 medium. These results indicate that fully supplemented culture medium is a more competitive environment for antigen binding due to the abundance of serum. To confirm these results basophil degranulation was also monitored using the embedded bioimpedance sensors. Fig. $\mathrm{S}-5 \mathrm{~b} \uparrow$ shows time- 
impedance traces of degranulation events using our silicon nitrate-coated integrated impedance biosensors. The observed increase in impedance signal by $0.175 \pm 0.03 \%$ following the addition of the $\mathrm{rPhI}$ antigen points at rapid basophil degranulation over a few minutes and the ability of the embedded impedance biosensors to detect transient cell responses in the range of seconds. Interestingly, impedance values rapidly normalized following media change to standard cell culture medium indicating efficient removal of rPhI antigen-containing media using the integrated micropumps, thus regranulation of basophil cells over the next period of 45 minutes. Another hallmark of type I allergy signaling cascade is concerned with endothelial cell responses to the release of histamine by basophil, which triggers the contraction of endothelial actomyosin fibers and results in vascular hyperpermeability. ${ }^{25}$ To evaluate endothelial cell responses in our lab-on-a-chip system, human endothelial cell monolayers are established over a 10 hours cultivation period and exposed to two subsequent additions of $30 \mu \mathrm{M}$ histamine. Impedance-time traces shown in Fig. $\mathrm{S}-5 \mathrm{c} \dagger$ reveal a rapid signal drop by $1.1 \%$ within the first 10 minutes of histamine exposure followed by a slow recovery upon histamine removal over a period of 60 min pointing at a slow regeneration of a tight endothelial barrier. A sequential second histamine exposure resulted in a similar decrease of resistance thus increases in permeability by around $0.9 \%$ within another 10 $\min$.

\subsection{On-chip monitoring of transient inflammatory cell-to-cell interactions}

In a final set of experiments, the allergy-on-a-chip system containing integrated liquid handling and embedded impedance biosensors was used to non-invasively monitor the cascade of transient cell-to-cell interactions that take place during IgE mediated type I allergic responses between basophil, endothelial and smooth muscle cells. Fig. 3a shows that within seconds of antigen exposure and cross-linking, opsonized RBL-2H3 basophils release inflammatory mediators to the underlying HUVEC endothelial cells. In turn, these endothelial cells react within 2 minutes with a decrease in impedance by $0.2 \%$ because of endothelial permeability. In the absence of rPhI antigen, no transient cellular responses were observable between basophils and endothelial cells. Additionally, impedance-time traces demonstrate that no alterations on the permeability of endothelial barriers are observed when using unprimed basophil cells (no IgE opsonization took place) even in the presence of the antigen. Impedance signals dropped by $0.7 \%$ within 5 minutes following the addition of $1 \mu \mathrm{g} \mathrm{ml}^{-1}$ rPhI antigen to a co-culture of IgE opsonized basophils and endothelial cells as shown in Fig. S-5e. $\uparrow$ These results point at efficient yet highly transient cell-to-cell communication between basophil and endothelial cell monolayers.

Finally, the direct influence of endothelial hyperpermeability on vascular smooth muscle cells responses was investigated to determine the time-dependence of cellu- a
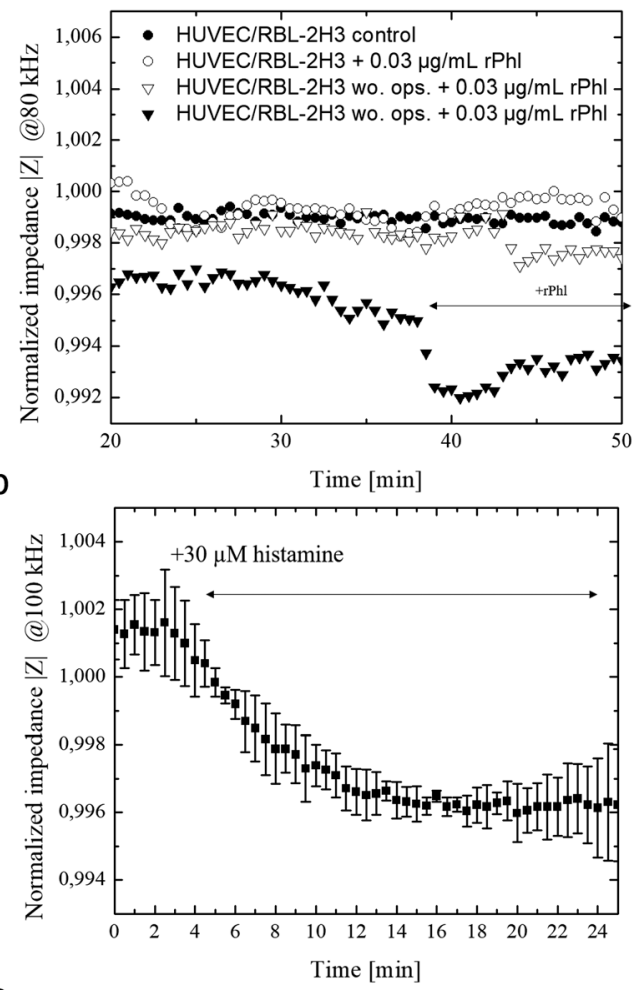

C

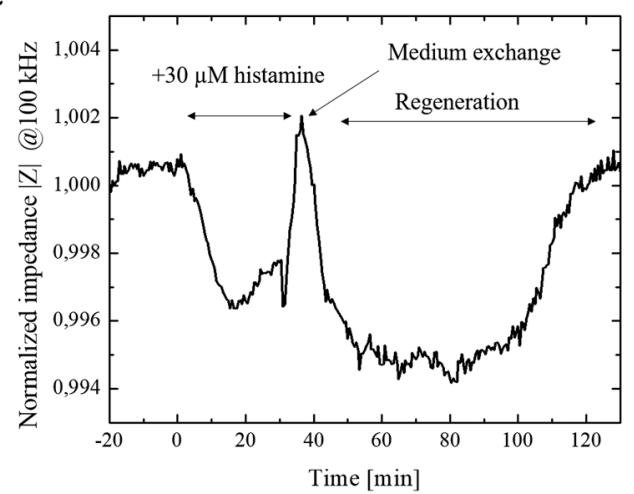

Fig. 3 (a) Impedance time-traces of $\mathrm{rPhl}$ antigen-mediated transient endothelial cell responses in the presence and absence of $r P h l$ antigen and $\operatorname{lgE}$ opsonization. The RBL-2H3 basophil co-culture on top of HUVEC monolayer was stimulated with $\mathrm{rPhl}$ antigen. (b and c) Impedance time-traces of double-layered HUVEC-vascular smooth muscle cell co-culture with cell relaxation $(n=2)$ as response to histamine mediated endothelial hyperpermeability and consecutive regeneration phase at a frequency of $100 \mathrm{kHz}$.

lar reactions within the signal transduction cascades. To create a multi-layered cell construct that resembles vasculature, vascular smooth muscle cells and endothelial cells were sequentially layered on top of each other using the integrated liquid handling system. Here, smooth muscle cells were first seeded at confluency and after $24 \mathrm{~h}$, a monolayer of endothelial cells was seeded on top, and cells were allowed form a monolayer over the smooth muscle cell layers (see Fig. S-6†). As a simplified model for allergic response cascade, $30 \mu \mathrm{M}$ histamine was added to the vascular construct and 
morphology changes of the underlying smooth muscle layer detected using the embedded electrical microsensors. Results of the endothelial cell-to-smooth muscle cell interaction study are shown in Fig. $3 \mathrm{~b}$ and c, revealing an impedance signal drop by $0.4 \%$ within 15 minutes of histamine exposure indicating vascular hyperpermeability, loss of barrier integrity and stimulation of smooth muscle cells. Overall, a delay in cellular histamine response time from a few minutes to 28 min is obtained when using our smooth muscle co-culture model compared to endothelial monolayers. These results highlight that the proposed integrated lab-on-a-chip approach is capable to investigate transient cell-co-cell interactions via biomolecules more rapidly within minutes in comparison to state-of-the-art electrical biosensing approaches that need several hours. ${ }^{42}$

\section{Conclusions}

In conclusion, the developed highly integrated and multifunctional lab-on-a-chip technology containing embedded liquid handling and biosensing is able to monitor transient cell-to-cell responses in the range of seconds to hours. We show here that the combination of micropumps anddegassers enables robust automated cell culture handling, rapid cell stimulation using nanoliter dosing as well as elimination of microbubbles, while automated seeding of multiple cell layers enables spatial organization of vascular co-culture models. We demonstrated that our highly integrated lab-ona-chip enables the translation of rapid and small cell responses such as release of histamine by basophile cells into readily measurable muscle contractions by microfluidic connection of a vascular co-culture model to an immune cell compartment. This scalable and automated technology has the potential to accelerate development of more effective and fast-acting allergy therapeutics.

\section{Author contributions}

All authors conceived and discussed the manuscript. P. E., R. A. M., R. N., V. C., H. W. and D. S. designed and performed the experiments. V. C., D. S. and M. R. analyzed data. M. R., B. B. and P. E. wrote the manuscript and all authors edited the manuscript. P. E. and R. A. M. supervised the project.

\section{Conflicts of interest}

There are no conflicts to declare.

\section{Acknowledgements}

The authors thank BioSensor Technologies unit of AIT Austrian Institute of Technology GmbH (Vienna) and the Medical University Vienna for supporting the project. Rudolf Valenta kindly provided basophil cells, antibodies and antigens.

\section{Notes and references}

1 G. M. Cooper, The Cell - A Molecular Approach, Sinauer Associates, Sunderland (MA), 2nd Edition, 2000.

2 E. Taverna, M. Götz and W. B. Huttner, Annu. Rev. Cell Dev. Biol., 2014, 30, 465-502.

3 O. Tornavaca, M. Chia, N. Dufton, L. O. Almagro, D. E. Conway, A. M. Randi, M. A. Schwartz, K. Matter and M. S. Balda, J. Cell Biol., 2015, 208(6), 821-838.

4 V. J. Thannickal and B. L. Fanburg, Am. J. Physiol., 2000, 279, L1005-L1028.

5 Q. Shen, Y. Wang, E. Kokovay, G. Lin, S.-M. Chuang, S. K. Goderie, B. Roysam and S. Temple, Cell Stem Cell, 2008, 3, 289-300.

6 G. Folco and R. C. Murphy, Pharmacol. Rev., 2006, 58, 375-388.

7 M. E. Gleave, J. T. Hsieh, A. C. Von Eschenbach and L. W. K. Chung, J. Urol., 1992, 147, 1151-1159.

8 K. Masaki, Neuropathology, 2015, 35, 469-480.

9 K. Kamińska, C. Szczylik, Z. F. Bielecka, E. Bartnik, C. Porta, F. Lian and A. M. Czarnecka, J. Cell. Mol. Med., 2015, 19, 283-296.

10 A. G. Clark and D. M. Vignjevic, Curr. Opin. Cell Biol., 2015, 36, 13-22.

11 J. Panés and D. N. Granger, Gastroenterology, 1998, 114, 1066-1090.

12 N. V. Valeyev, C. Hundhausen, Y. Umezawa, N. V. Kotov, G. Williams, A. Clop, C. Ainali, C. Ouzounis, S. Tsoka and F. O. Nestle, PLoS Comput. Biol., 2010, 6, e1001024.

13 D. L. Chao, L. Ma and K. Shen, Nat. Rev. Neurosci., 2009, 10, 262.

14 Y. Choi, R. Faccio, S. L. Teitelbaum and H. Takayanagi, in Osteoimmunology, ed. J. Lorenzo, M. C. Horowitz, Y. Choi, H. Takayanagi and G. Schett, Academic Press, San Diego, 2nd edn, 2016, pp. 41-70, DOI: 10.1016/B978-0-12-800571-2.00004-9.

15 M. I. Cuartero, I. Ballesteros, I. Lizasoain and M. A. Moro, Brain Res., 2015, 1623, 53-62.

16 B. Rossboth, A. M. Arnold, H. Ta, R. Platzer, F. Kellner, J. B. Huppa, M. Brameshuber, F. Baumgart and G. J. Schutz, Nat. Immunol., 2018, 19, 821-827.

17 L. Zhong, J. Roybal, R. Chaerkady, W. Zhang, K. Choi, C. A. Alvarez, H. Tran, C. J. Creighton, S. Yan, R. M. Strieter, A. Pandey and J. M. Kurie, Cancer Res., 2008, 68, 7237-7245.

18 C. M. Howard and T. A. Baudino, J. Mol. Cell. Cardiol., 2014, 70, 19-26.

19 G. A. W. Rook and J. L. Stanford, Immunol. Today, 1998, 19, 113-116.

20 P. T. C. A. Janeway Jr., M. Walport and M. J. Shlomchik, Immunobiology: The Immune System in Health and Disease, Garland Science, 5th edn, 2001.

21 D. G. Waller and A. P. Sampson, in Medical Pharmacology and Therapeutics, ed. D. G. Waller and A. P. Sampson, Elsevier, 5th edn, 2018, pp. 439-449, DOI: 10.1016/B978-07020-7167-6.00038-5.

22 J. Wedemeyer, M. Tsai and S. J. Galli, Curr. Opin. Immunol., $2000,12,624-631$. 
23 K. D. Stone, C. Prussin and D. D. Metcalfe, J. Allergy Clin. Immunol., 2010, 125, S73-S80.

24 J. T. Schroeder, Immunol. Rev., 2011, 242, 144-160.

25 M. V. White, J. Allergy Clin. Immunol., 1990, 86, 599-605.

26 T. A. Platts-Mills, J. Allergy Clin. Immunol., 2015, 136, 3-13.

27 R. Valenta, R. Campana, M. Focke-Tejkl and V. Niederberger, J. Allergy Clin. Immunol., 2016, 137, 351-357.

28 H. Zirath, M. Rothbauer, S. Spitz, B. Bachmann, C. Jordan, B. Müller, J. Ehgartner, E. Priglinger, S. Mühleder, H. Redl, W. Holnthoner, M. Harasek, T. Mayr and P. Ertl, Front. Physiol., 2018, 9, 815.

29 M. Rothbauer, J. M. Rosser, H. Zirath and P. Ertl, Curr. Opin. Biotechnol., 2018, 55, 81-86.

30 M. Rothbauer, H. Zirath and P. Ertl, Lab Chip, 2018, 18, 249-270.

31 B. Bachmann, S. Spitz, M. Rothbauer, C. Jordan, M. Purtscher, H. Zirath, P. Schuller, C. Eilenberger, S. F. Ali, S. Mühleder, E. Priglinger, M. Harasek, H. Redl, W. Holnthoner and P. Ertl, Biomicrofluidics, 2018, 12, 042216.

32 Y. F. S. Seah, H. Hu and C. A. Merten, Mol. Aspects Med., 2018, 59, 47-61.
33 Y. Yanase, K. Sakamoto, K. Kobayashi and M. Hide, Opt. Mater. Express, 2016, 6, 1339-1348.

34 J. Sinurat, I. Rengganis, C. M. Rumende and K. Harimurti, Asia Pac. Allergy, 2018, 8(1), e10.

35 Q. Ramadan and M. A. Gijs, Lab Chip, 2015, 15, 614-636.

36 V. Charwat, M. Rothbauer, S. F. Tedde, O. Hayden, J. J. Bosch, P. Muellner, R. Hainberger and P. Ertl, Anal. Chem., 2013, 85, 11471-11478.

37 V. Charwat, M. Joksch, D. Sticker, M. Purtscher, M. Rothbauer and P. Ertl, Analyst, 2014, 139, 5271-5282.

38 O. Y. F. Henry, R. Villenave, M. J. Cronce, W. D. Leineweber, M. A. Benz and D. E. Ingber, Lab Chip, 2017, 17, 2264-2271.

39 V. Charwat, M. Rothbauer, S. F. Tedde, O. Hayden, J. J. Bosch, P. Muellner, R. Hainberger and P. Ertl, Anal. Chem., 2013, 85, 11471-11478.

40 J. Kim, M. Kang, E. C. Jensen and R. A. Mathies, Anal. Chem., 2012, 84, 2067-2071.

41 J. Kim, A. M. Stockton, E. C. Jensen and R. A. Mathies, Lab Chip, 2016, 16, 812-819.

42 I. Bischof, M. C. Hornburger, B. A. Mayer, A. Beyerle, J. Wegener and R. Fürst, Sci. Rep., 2016, 6, 23671. 